\title{
A comparison of albumin removal procedures for proteomic analysis of blood plasma
}

\author{
Anna Tomascova ${ }^{1}$, Jan Lehotsky ${ }^{1,2}$, Dagmar Kalenska ${ }^{1}$, Eva Baranovicova ${ }^{2}$, Peter Kaplan ${ }^{1,2}$ \\ and Zuzana Tatarkova ${ }^{1}$ \\ ${ }^{1}$ Department of Medical Biochemistry, Jessenius Faculty of Medicine in Martin, Comenius University in Bratislava, Martin, Slovakia \\ ${ }^{2}$ Department of Neuroscience, Biomedical Centre Martin, Jessenius Faculty of Medicine in Martin, Comenius University in \\ Bratislava, Martin, Slovakia
}

\begin{abstract}
Blood biomarkers are usually present in low concentration and can be masked by the high-abundance proteins, of which albumin is the predominant one. The purpose of this study was to compare four different albumin removal methods compatible with in-gel based proteomics, applicable for plasma, without requiring specific techniques and high financial input. Plasma underwent albumin depletion with ultrafiltration device Amicon Ultra, commercial ProteoPrep Blue Albumin and IgG Depletion Kit, acetonitrile precipitation method and precipitation with acetonitrile-methanol protocol. All samples were evaluated by 1-D and 2-D gel electrophoresis with subsequent mass spectrometry protein identification. Two of the tested methods (ProteoPrep BlueKit and acetonitrilemethanol precipitation) maintained sufficient protein content for further in-gel analyses. Their 2-D protein profiles were distinctively separated and overlapped with protein profile of crude plasma. Protein spot count showed significant increase in protein spots, compared to crude plasma, only with acetonitrile-methanol precipitation method. Precipitation with acetonitrile-methanol method significantly increased number of protein spots on 2-D protein profile and improved score of mass spectrometry identification. However, albumin was still present and found in number of protein spots.
\end{abstract}

Key words: Albumin removal — Mass spectrometry - Biomarkers - Blood plasma

\begin{abstract}
Abbreviations: 1-DE, one-dimensional electrophoresis; 2-DE, two-dimensional electrophoresis; $\mathrm{ABC}$, ammonium bicarbonate; ACN, acetonitrile; AMW, acetonitrile-methanol-water; BSA, bovine serum albumin; HAPs, high-abundance proteins; IEF, isoelectric focusing; LAPs, low-abundance proteins; MS, mass spectrometry; MW, molecular weight; SDS-PAGE, sodium dodecyl sulphatepolyacrylamide gel electrophoresis.
\end{abstract}

\section{Introduction}

In clinical practice, blood samples are routinely used for wide range of diagnostic purposes as they are easily obtained and can be repetitively sampled. Proteins in circulatory system

Electronic supplementary material. The online version of this article (doi: 10.4149/gpb_2019009) contains supplementary material, which is available to authorized users.

Correspondence to: Zuzana Tatarkova, Department of Medical Biochemistry, Jessenius Faculty of Medicine, Mala Hora 4, 03601 Martin, Slovakia

E-mail: Zuzana.Tatarkova@jfmed.uniba.sk reflect person's physiology. Changes in concentration of certain proteins or their post-translational modification reflect particular disease state and could be used as diagnostic and prognostic biomarkers (Anderson and Anderson 2002).

However, discovery of new blood protein biomarkers faces difficulties, as approx. 95\% of bulk mass of proteins is made up of few high-abundance proteins (HAPs), predominantly albumin (Fang and Zhang 2008). They produce large signals that can mask or interfere with the detection of low abundant biomarkers (Roche et al. 2009). Around half of the protein mass in blood serum and plasma consists of albumin, and low-abundance proteins (LAPs) are likely to be in concentration of five to ten orders of magnitude 
lower $(<<10 \mathrm{ng} / \mathrm{ml})$. Moreover, albumin is a known carrier and transporter of physiologically important proteins and peptides, so it is important to note that its removal can result in loss of potential biomarkers (Tirumalai 2003).

Rodents represent highly controllable model and an important part of biomarker discovery. Particularly rats and mice are commonly used in various medical research areas (Hood et al. 2005; Linke et al. 2007). Rodent blood proteome has its own specific profile but similar wide dynamic range in protein concentrations as human blood and therefor presents the same challenges in proteomic research (Haudenschild et al. 2014). Rat blood profiles show that albumin and IgG make up about $80 \%$ of total plasma protein and their depletion could result in significant increase of concentration of medium-abundance proteins and LAPs (Sharp and LaRegina 1998).

Removal of albumin and other HAPs from blood plasma or serum is necessary step prior implementing proteomic methods for biomarker discovery. There is a number of different approaches to remove albumin including immunoaffinity-mediated proteomic separation, centrifugal ultrafiltration, commercial kits based on Cibacron blue or precipitation in organic solvents (Tucholska et al. 2007; Holewinski et al. 2013; Qui et al. 2015). However, removal methods are often expensive and time consuming with limited sample capacity (Kay et al. 2008).

In present work, four different methods of albumin removal have been studied: centrifugal ultrafiltration device Amicon Ultra with protein cut-off limit of $50 \mathrm{kDa}$ (Merck Millipore), commonly used commercial ProteoPrep Blue Albumin and IgG Depletion Kit (Sigma-Aldrich) based on Cibacron Blue dye and two methods based on protein precipitation in organic solvents. These methods were compared using one-dimensional and two-dimensional gel electrophoresis (1-DE and 2-DE) with MALDI-TOF mass spectrometry (MS) protein identification. 2-DE coupled with MS identification is a common proteomic approach and was already successfully employed in blood biomarker studies of e.g. cervical, hepatocellular or colorectal carcinoma (Henkel et al. 2012; Guo et al. 2015; Lim et al. 2016). Our main goal was to see if commonly available and inexpensive organic solvent methods are comparable to those commercial ones and applicable for in-gel proteomic analyses.

\section{Materials and Methods}

\section{Animals}

A total number of 6 adult male Wistar rats (Velaz, Czech Republic) at the age of 3 months with mean weight of $335 \pm$ $42.7 \mathrm{~g}$ were used in this study. They were housed in a temperature-controlled room $22 \pm 2^{\circ} \mathrm{C}$ on a 12-h light/dark cycle with access to food and water ad libitum. All procedures on animals were performed in accordance with ethical and moral principles and approved by the State Veterinary and Food Department of the Slovak Republic and by Ethical Committee of Comenius University in Bratislava, Jessenius Faculty in Martin (\# 1647/2015).

\section{Sample collection}

Rat whole blood was collected in $6 \mathrm{ml}$ lithium heparincoated tubes (Vacutest Kima). Blood was centrifuged at $4^{\circ} \mathrm{C}, 720 \times g$ for $20 \mathrm{~min}$. Plasma was aliquoted and stored at $-80^{\circ} \mathrm{C}$ until analysis.

\section{Methods of albumin removal}

We compared four different methods that remove albumin to determine the most suitable one for in-gel methods. All samples were kept on ice and manipulations were performed at room temperature if not stated otherwise.

\section{Albumin removal with Amicon Ultra-0.5 centrifugal filter $50 \mathrm{~K}$ device}

The Amicon Ultra-0.5 Centrifugal Filter Device (UFC505096, Millipore) with cut-off limit of $50 \mathrm{kDa}$ was used according to manufacturer's instructions with $400 \mu \mathrm{l}$ of plasma samples. Spin time of $15 \mathrm{~min}$ was used after testing 15, 20 and $30 \mathrm{~min}$ spin time with no significant difference in concentration yield. Depleted plasma filtrate was used for further analyses. The cut-off limit (device capturing molecules $\geq 50 \mathrm{kDa}$ ), was picked in compliance with the molecular weight (MW) of rat albumin of $70.7 \mathrm{kDa}$.

\section{Albumin removal with ProteoPrep Blue Albumin and IgG Depletion Kit}

Albumin removal with ProteoPrep Blue Albumin and IgG Depletion Kit (PROTBA, Sigma-Aldrich) was performed according to manufacturer's instructions with $50 \mu \mathrm{l}$ of plasma. Both fractions, depleted plasma and albumin-enriched protein extract were used for further analyses.

\section{Albumin removal with acetonitrile protocol (ACN Protocol)}

Albumin removal was carried out according to protocol described by Kay et al. (2008) and Fernandez et al. (2011). A total volume of $150 \mu$ l of each plasma sample was divided into three aliquots. In $1.5 \mathrm{ml}$ disposable microcentrifuge tubes $50 \mu \mathrm{l}$ of plasma was diluted with $100 \mu \mathrm{l}$ LC-MS grade $\mathrm{H}_{2} \mathrm{O}$ and briefly vortexed. To each aliquot $225 \mu \mathrm{l}$ of $100 \%$ acetonitrile (ACN) was added and the samples were sonicated in ultrasonic bath for $10 \mathrm{~min}$, vortexed briefly and 
sonicated for another $10 \mathrm{~min}$. Samples were centrifuged at $14,000 \times g$ for $10 \mathrm{~min}$ at room temperature. Supernatants from the aliquots were pooled in clean microcentrifuge tubes and evaporated to dryness in vacuum concentrator centrifuge (Concentrator plus/Vacufuge plus, Eppendorff), reconstituted in $150 \mu$ of sample buffer $(0.2 \mathrm{~mol} / \mathrm{l}$ Tris- $\mathrm{HCl}$ pH 6.8, 2\% SDS 20\% glycerol) and used for further analyses. This protocol was repeated several times to reach necessary protein content for electrophoresis. The pellets containing removed albumin and other high-abundance proteins did not dissolve in buffer solution and hence were impossible to analyse with in-gel methods.

\section{Albumin removal with acetonitrile-methanol-water protocol (AMW Protocol)}

Albumin removal was performed according to slightly adjusted protocol previously described by Tucholska et al. (2010). In $1.5 \mathrm{ml}$ disposable microcentrifuge tubes $25 \mu \mathrm{l}$ of plasma samples were precipitated with five volumes of $100 \%$ ACN, vortexed and incubated on ice for $15 \mathrm{~min}$. Samples were centrifuged at $16,000 \times g$ for $15 \mathrm{~min}$ and supernatants were transferred to clean microcentrifuge tubes. Pellets were resuspended in $50 \mu \mathrm{l}$ of AMW solution $(12.5 \mu \mathrm{l}$ of $100 \%$ acetonitrile, $12.5 \mu \mathrm{l}$ of $100 \%$ methanol and $25 \mu \mathrm{l}$ of LC-MS grade $\mathrm{H}_{2} \mathrm{O}$ ), incubated on ice for $15 \mathrm{~min}$ and centrifuged at 16,000 $\times g$ for $15 \mathrm{~min}$. Supernatants were added to their previous fractions. Pellets with depleted plasma proteins were left to dry for $20 \mathrm{~min}$ at room temperature, reconstituted with $200 \mu \mathrm{l}$ of acidified water with $1 \%$ formic acid and mixed on shaker $\left(20^{\circ} \mathrm{C}, 2\right.$ hours, shaking slightly). Supernatants with removed albumin fraction were evaporated to dryness in vacuum concentrator centrifuge and also reconstituted with acidified water. Both fractions were used in further analyses.

\section{Protein assay}

To determine total protein content, DC Protein Assay (500-0111, Bio-Rad) in a microplate format was performed according to manufacturer's instructions.

\section{One-dimensional electrophoresis (1-DE)}

Samples (30 $\mu \mathrm{g}$ of protein content) were precipitated with ice-cold acetone and centrifuged at $16,000 \times g$ for $10 \mathrm{~min}$. After protein reconstitution in $30 \mu$ l of loading buffer $(0.2 \mathrm{M}$ Tris- $\mathrm{HCl}$ pH 6.8, 2\% SDS 20\% glycerol, 0.1\% bromophenol blue) samples were boiled for $4 \mathrm{~min}$ at $96^{\circ} \mathrm{C}$. Proteins were separated using sodium dodecyl sulphate-polyacrylamide gel electrophoresis (SDS-PAGE) with 12\% gels under denaturing conditions using a Bio-Rad mini electrophoresis system in tricine electrophoresis buffer. SDS-PAGE was carried out at $15 \mathrm{~mA}$ until the bromophenol blue dye reached the bottom of the gel. Gel was stained using Bio-Safe Coomassie G-250 stain (161-0786, Bio-Rad) and scanned by GS-800 Calibrated Densitometer (Bio-Rad).

\section{Two-dimensional electrophoresis (2-DE)}

Samples $(200 \mu \mathrm{g}$ of protein content) were precipitated with ice-cold acetone and pelleted by centrifugation $(16,000 \times g$ for $10 \mathrm{~min})$. After protein reconstitution in Rehydration/ Sample buffer (163-2106, Bio-Rad), they were applied to 7 cm linear ReadyStrip IPG strips with pH 3-10 (163-2000, Bio-Rad) and let to rehydrate overnight. Isoelectric focusing (IEF) was performed using Protean IEF system (Bio-Rad) in three-step protocol (250 V for $20 \mathrm{~min}, 4000 \mathrm{~V}$ for 2 hours and $4000 \mathrm{~V}$ until the total voltage reached $10,000 \mathrm{Vh}$ ). Prior to the second dimension separation, the strips were equilibrated in Equilibration Buffer I (163-2107, Bio-Rad) for $15 \mathrm{~min}$ and in Equilibration Buffer II (163-2108, Bio-Rad) with added $0.03 \mathrm{~g} / \mathrm{ml}$ iodoacetamide for $15 \mathrm{~min}$. Following equilibration, the IPG strips were placed on $12 \%$ polyacrylamide gels and covered with overlay agarose (163-2111, BioRad). SDS-PAGE ran for $20 \mathrm{~min}$ at $15 \mathrm{~mA}$ and at $25 \mathrm{~mA}$ until the bromophenol blue dye reached the bottom of the gel using a Bio-rad mini electrophoresis system in tricine electrophoresis buffer. Gels were stained using Bio-Safe Coomassie G-250 stain (161-0786, Bio-Rad), scanned by GS-800 Calibrated Densitometer (Bio-Rad) and analysed using PDQuest 8 software (Bio-Rad).

\section{Protein identification by mass spectrometry}

Protein spots/bands were excised from gels, washed with $50 \% \mathrm{ACN}$ at room temperature until Coomassie stain was removed and dehydrated in $100 \%$ ACN. Spots were then incubated with $10 \mathrm{mM}$ dithiotreitol at $56^{\circ} \mathrm{C}$ for $45 \mathrm{~min}$ to reduce disulphide bridges and in $55 \mathrm{mM}$ iodoacetamide for 30 min in dark to alkylate cysteine residues. Next, spots/ bands were washed two times with $25 \mathrm{mM}$ ammonium bicarbonate $(\mathrm{ABC})$ and $100 \% \mathrm{ACN}$ alternatively. For protein digestion, $3 \mu \mathrm{l}$ of trypsin solution $(20 \mathrm{ng} / \mu \mathrm{l}$ in $\mathrm{ABC}$, Promega) was added directly on the spot/band and incubated for $30 \mathrm{~min}$ on ice. Subsequently $20 \mu \mathrm{l}$ of ABC were added and incubated overnight at $37^{\circ} \mathrm{C}$ on shaker. Peptides were extracted with $10 \%$ trifluoroacetic acid, dehydrated with $100 \%$ ACN and collected samples were concentrated in vacuum concentrator centrifuge until final volume reached approx. $10 \mu \mathrm{l}$. Next, $0.75 \mu \mathrm{l}$ of sample was applied onto AnchorChip target (Bruker Daltonics) and when dried down, $0.75 \mu \mathrm{l}$ of matrix solution ( $\alpha$-cyano- 4 hydroxy cinnamic acid, $1 \mathrm{mg} / \mathrm{ml}$ ) was added and left to dry. For calibration purposes, Peptide Calibration Standard (8206195, Bruker Daltonics) was applied onto AnchorChip in the same manner as the samples. 


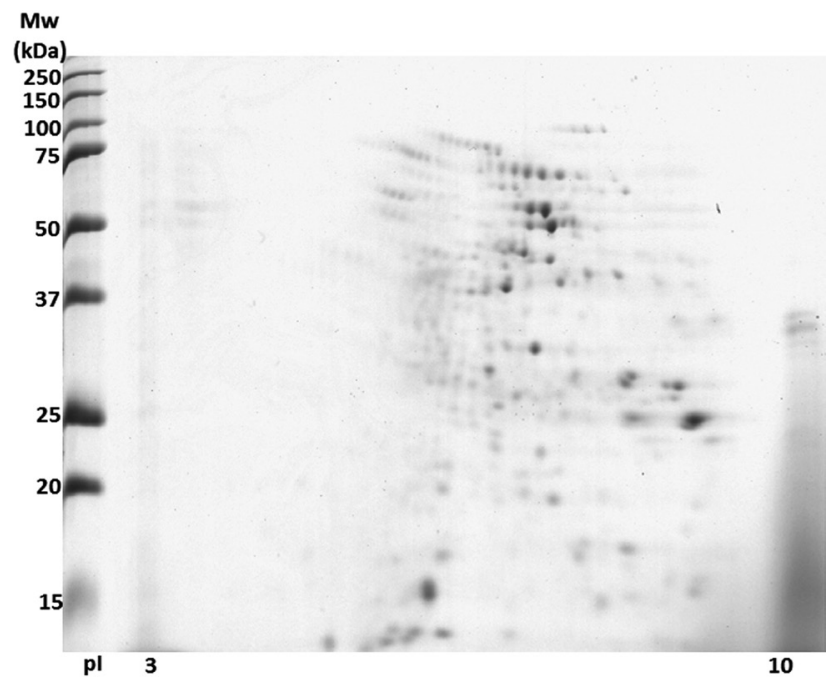

Figure 1. Representative 2-DE SDS-PAGE map of plasma depleted with Amicon filter device. Result is representative of three independent experiments.

The mass spectra were recorded on an UltrafleXtreme MALDI-TOF/TOF mass spectrometer (Bruker Daltonics) across $\mathrm{m} / \mathrm{z}$ range $700-3500 \mathrm{kDa}$. MS/MS fragmentation spectra were obtained by selecting three strongest peaks of each peptide mass map. The SwissProt database was searched using MASCOT database search engine (Matrix Science: www.matrixscience.com/help/scoring_help.html) with following parameters: enzyme trypsin; taxonomy Rattus norvegicus, mass tolerance for PMF 50 ppm and one missing cleavage, MS/MS tolerance $0.5 \mathrm{Da}$, global modification carbamidomethylation $(\mathrm{C})$ and variable modification oxidation: methionine oxidation $(\mathrm{M})$.

\section{Results}

\section{Protein content}

Total protein content in crude plasma was $69.10 \pm 8.46 \mathrm{mg} \mathrm{ml}$. Measured protein concentration of plasma after undergoing individual albumin removal protocols is summarized in Tab. 1. Using ProteoPrep kit and AMW protocol, depleted plasma maintained nearly $50 \%$ of its protein content. After depletion with Amicon filter device protein content in depleted fraction was reduced nearly 600 -fold and after ACN protocol about 200 fold. Loss in total protein content (depleted fraction + albuminenriched fraction) might result from numerous manipulations.

\section{Albumin removal with Amicon Ultra-0.5 Centrifugal Filter 50 K Device}

Due to low total protein yield, Amicon filter device was excluded from further experiments. A representative 2-DE protein map with protein load of $90 \mu \mathrm{g}$ is shown on Fig. 1.

After decapitation, 4-6 ml of blood from a single animal is obtained, leading to less than half volume of plasma. For one 2-DE map with standard protein load of $200 \mu \mathrm{g}$, approx. 1600 $\mu \mathrm{l}$ of crude plasma would be needed, making this method unsuitable for in-gel proteomics.

\section{One-dimensional electrophoresis}

Efficiency of removal methods was evaluated using 1-D electrophoresis. The SDS-PAGE visualised the most abundant proteins in both, depleted and albumin-enriched fractions (Fig. 2). The gel bands corresponding to albumin were less dense in samples that underwent the removal methods (Fig. 2B, 2C, 2D) compared to the crude serum (Fig. 2A).

ProteoPrep kit (Fig. 2E) captured mostly albumin and in part hemopexin and serotransferrin. In albumin-enriched fraction from AMW protocol can be found except from high albumin concentration, hemopexin, serotransferrin, vitamin D-binding protein and apolipoproteins. During acetonitrile washing steps hydrophobic proteins, mainly apolipoproteins can be removed from the plasma together with albumin. Proteins representing the bands were characterised using MALDI-TOF/TOF (for mass spectrometry identification details see Tab. S1 in Supplementary Material).

\section{Two-dimensional electrophoresis}

Proteins from crude plasma and different albumin removal methods (ProteoPrep kit depletion, AMW and ACN removal protocols) were analysed using 2-DE (Fig. 3). When compared to crude plasma, protein spot count revealed significant increase in number of visualised spots after applying

Table 1. Protein content measured in individual fractions in plasma after undergoing different albumin depletion methods

\begin{tabular}{lccc}
\hline & \multicolumn{2}{c}{ Removal method } \\
\cline { 2 - 4 } Fraction & $\begin{array}{c}\text { Amicon filter device } \\
(\mathrm{mg} / \mathrm{ml})\end{array}$ & $\begin{array}{c}\text { ProteoPrep kit } \\
(\mathrm{mg} / \mathrm{ml})\end{array}$ & $\begin{array}{c}\text { AMW protocol } \\
(\mathrm{mg} / \mathrm{ml})\end{array}$ \\
\hline Depleted fraction & $0.12 \pm 0.03$ & $28.33 \pm 1.97$ & $32.93 \pm 8.17$ \\
Albumin-enriched fraction & $28.65 \pm 5.51$ & $7.68 \pm 2.63$ & $3.79 \pm 0.36$ \\
\hline
\end{tabular}


AMW protocol and surprisingly decrease after ProteoPrep and ACN depletion. Spot count for each method is summarised in Tab. 2.

In region with high occurrence of albumin, that often covers other proteins (MW $50-75 \mathrm{kDa}$ ), 15 protein spots were selected for identification with MALDI-TOF/TOF (Fig. 3, see zoomed region). Results from protein identifications are summarized in Tab. 3 (for mass spectrometry identification details see Tab. S2-S4 in Supplementary Material). Success of protein identification was determined by Mascot score which is a probability-based scoring to judge whether a result is significant or not. In general, scores greater than 67 are considered significant $(p<0.05)$ (Matrix Science 2016).

In crude plasma (Fig. 3A), we identified albumin (ALBU_ RAT) in 7 spots, one of them (spot no. 6) in a mixture with T-kininogen (KNT1_RAT). Highly prevalent were also fibrinogen isoforms (FIBA_RAT and FIBB_RAT), together in 6 spots. Out of the selected spots, we were not able to identify proteins in spot no. 5 due to insufficient number of matched peptides. Protein in spot no. 8 , actin-related protein $2 / 3$ complex subunit 1A (ARC1A_RAT), was identified with low Mascot score (see Tab. 3) and its MW and pI (42.1 kDa and 8.46) does not correlate with its position on the protein map making the result unreliable.

After applying ProteoPrep kit (Fig. 3B), albumin was found only in two spots and spots with fibrinogen isoforms decreased to three. Spot no. 4 was not identified. Previously not identified spot no. 5 was discerned as tubulin beta- 3 chain (TBB3_RAT) but with low Mascot score. Only 8 spots reached Mascot score above 67 (Tab. 3). Most of the proteins
Table 2. Number of protein spots detected in the crude plasma sample and after different albumin removal methods

\begin{tabular}{lc}
\hline Removal method & Number of spots \\
\hline Crude plasma & $213 \pm 9$ \\
ProteoPrep kit & $181 \pm 21$ \\
AMW protocol & $261 \pm 8$ \\
ACN protocol & $149 \pm 14$ \\
\hline
\end{tabular}

with low Mascot score were not concentrated in the supposed position of the identified proteins.

When using AMW protocol (Fig. 3C), all 15 protein spots were identified with Mascot score above 67. We identified albumin in six spots and fibrinogen isoforms in four spots. Albumin was removed from spot no. 4 and no. 6 . Spot no. 4 was after AMW removal identified as transferrin (TRFE_RAT). Spot no. 6 was identified as KNT1_RAT as well as spot no. 5, previously unidentified in crude plasma. Moreover, protein in spot no. 8 , which was in crude plasma identified with very low Mascot score, was depicted as fibrinogen gamma (FIBG_RAT) with sufficient score (Tab. 3).

We were not able to find all 15 selected protein spots in ACN protein maps (Fig. 3D). Overall protein profile of depleted sample was significantly changed and did not overlap with that of crude plasma. Furthermore, only the spot identified as albumin (ALBU_RAT) reached Mascot score over 67 . The rest of excised protein spots demonstrated low Mascot score (Tab. 3).

Proteins in albumin-enriched fractions from ProteoPrep kit (Fig. 4A) and AMW protocol (Fig. 4B) were also visu-

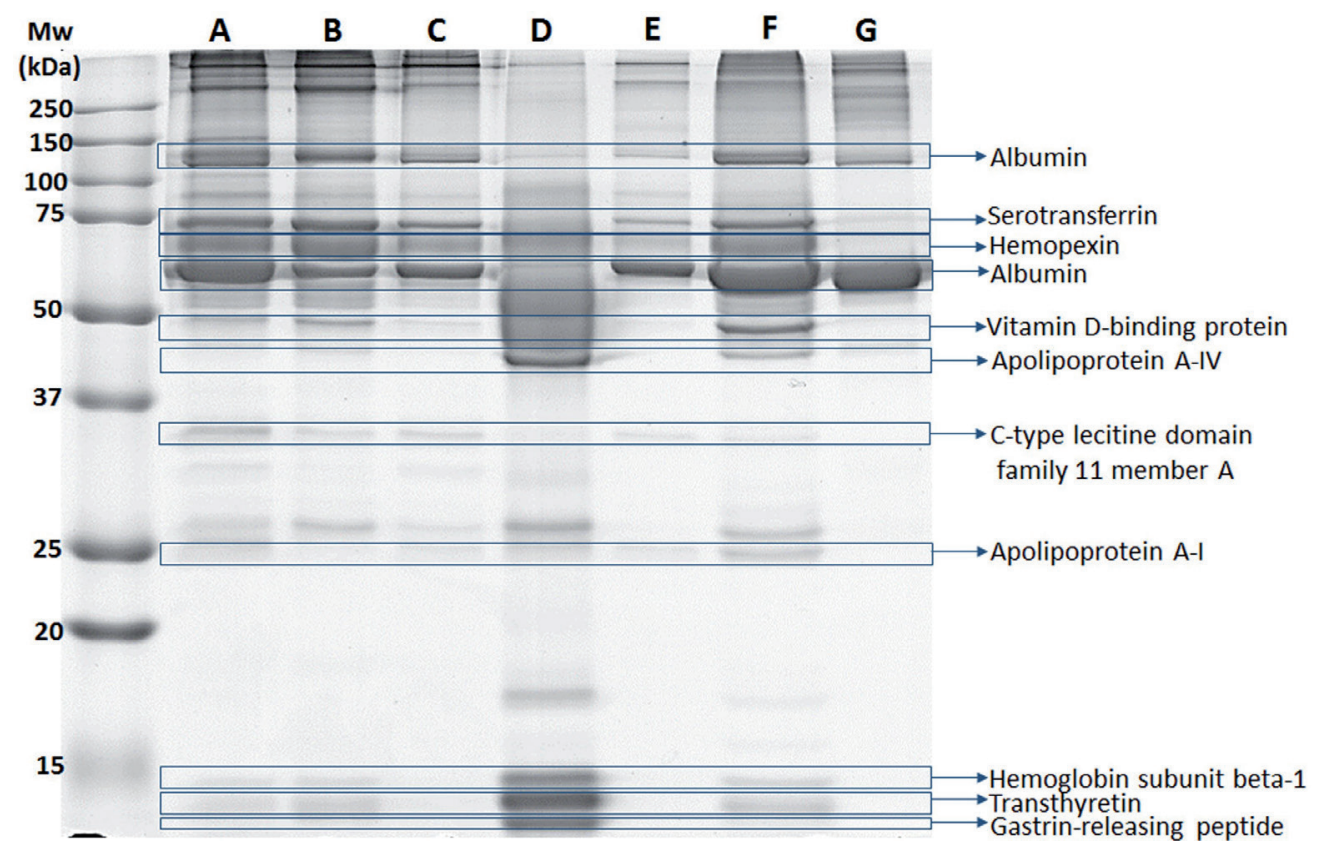

Figure 2. 1-DE SDS-PAGE analysis of the different albumin removal methods: A, crude plasma; B, ProteoPrep kit depletion; C, AMW protocol depletion; $\mathrm{D}, \mathrm{ACN}$ protocol depletion; E, albumin-enriched fraction from ProteoPrep kit; F, albumin-enriched fraction from AMW protocol; G, albumin positive control (BSA). AMW, acetonitrilemethanol-water; ACN, acetonitrile; BSA, bovine serum albumin. 


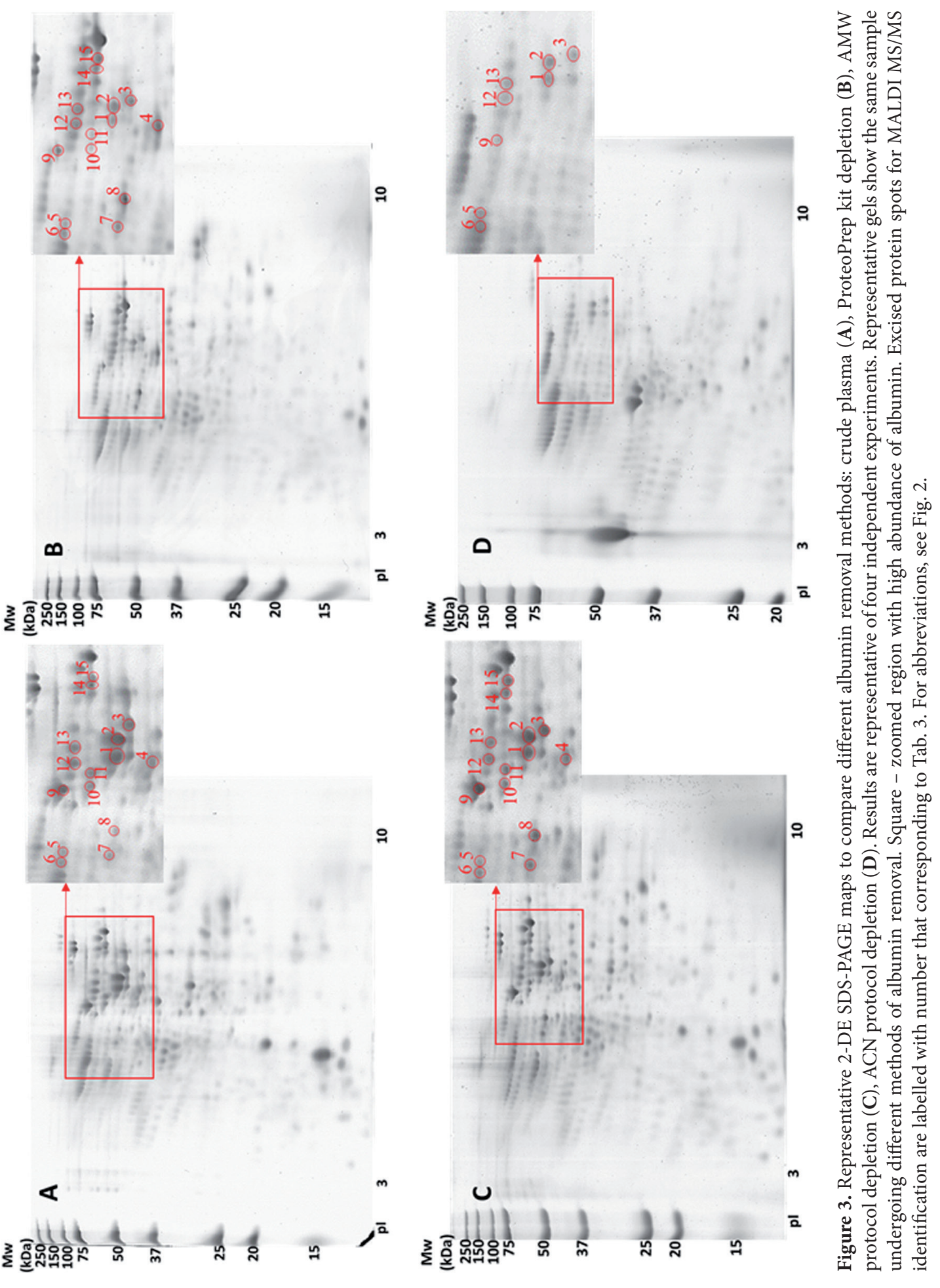



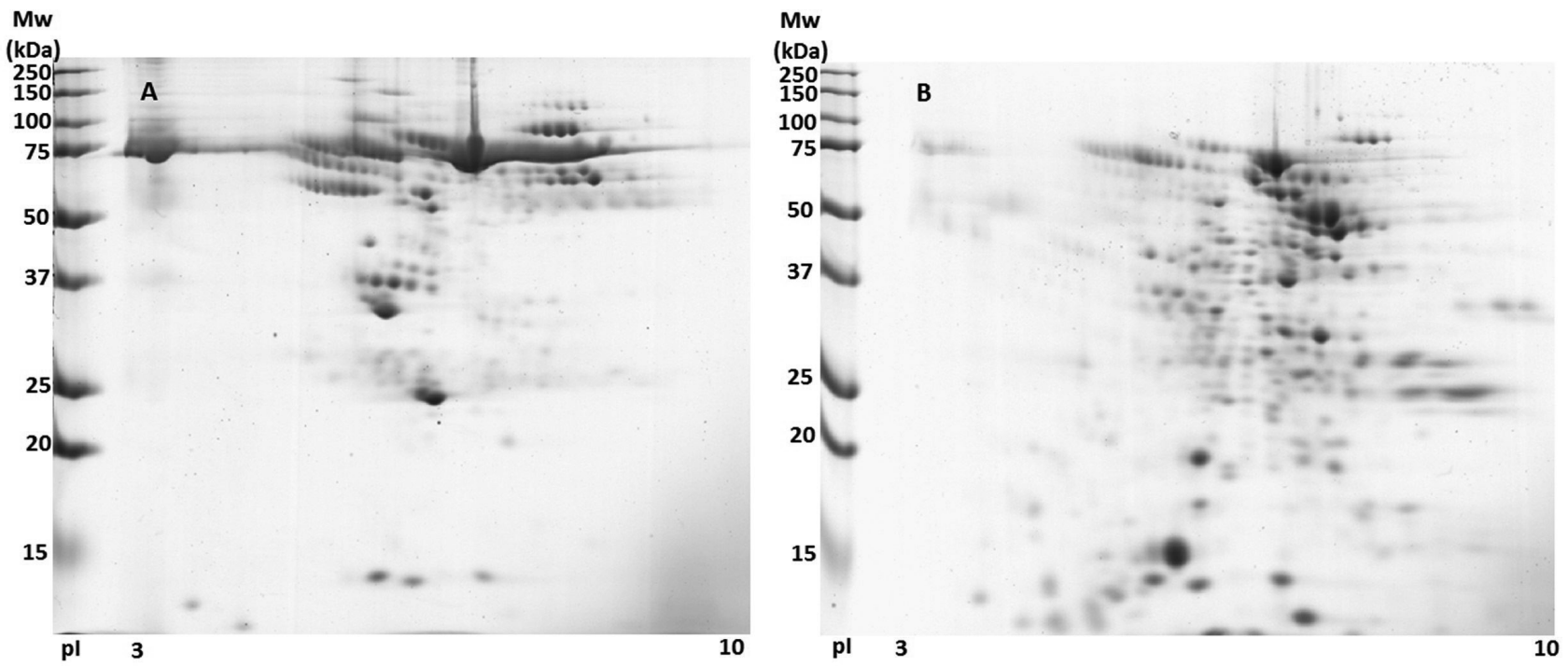

Figure 4. Albumin-enriched representative 2-DE maps: albumin-enriched fraction from ProteoPrep kit (A) and albumin-enriched fraction from AMW protocol (B). Results are representative of four independent experiments.

alised. Albumin-enriched fraction from ACN protocol was not analysed, as it was not possible to dissolve the resulting pellet in sample buffer. Protein map of ProteoPrep kit reten- tion (albumin-enriched fraction) shows high abundance of proteins with $\mathrm{Mw}$ over $50 \mathrm{kDa}$ with extensive cluster in place with expected albumin. Visualisation of proteins from

Table 3. Identified proteins from protein maps

\begin{tabular}{|c|c|c|c|c|c|c|c|c|}
\hline \multirow[b]{2}{*}{$\begin{array}{c}\text { Spot } \\
\text { No. }\end{array}$} & \multicolumn{2}{|c|}{ Crude plasma } & \multicolumn{2}{|c|}{ Commercial KIT } & \multicolumn{2}{|c|}{ AMW protocol } & \multicolumn{2}{|c|}{ ACN protocol } \\
\hline & UniProt ID & $\begin{array}{c}\text { Total } \\
\text { Mascot } \\
\text { score }\end{array}$ & UniProt ID & $\begin{array}{c}\text { Total } \\
\text { Mascot } \\
\text { score }\end{array}$ & UniProt ID & $\begin{array}{l}\text { Total } \\
\text { Mascot } \\
\text { score }\end{array}$ & UniProt ID & $\begin{array}{c}\text { Total } \\
\text { Mascot } \\
\text { score }\end{array}$ \\
\hline 1 & ALBU_RAT & 358 & RPN1_RAT $\Delta$ & 26 & ALBU_RAT & 419 & SP20H_RAT & 30 \\
\hline 2 & ALBU_RAT & 185 & ALBU_RAT & 277 & ALBU_RAT & 337 & ALBU_RAT & 258 \\
\hline 3 & ALBU_RAT & 231 & ALBU_RAT & 357 & ALBU_RAT & 288 & DO1L1_RAT ${ }^{\star} \Delta$ & 33 \\
\hline 4 & ALBU_RAT & 196 & $\mathrm{X}$ & $\mathrm{X}$ & TRFE_RAT ${ }^{\star}$ & 373 & KNT1_RAT ${ }^{*}$ & 32 \\
\hline 5 & $\mathrm{X}$ & $\mathrm{X}$ & TBB3_RAT ${ }^{\star 0}$ & 29 & KNT1_RAT* & 111 & KNT1_RAT ${ }^{*}$ & 48 \\
\hline 6 & $\begin{array}{l}\text { Mixture } \\
\text { KNT1_RAT }^{*} \\
\text { ALBU_RAT }\end{array}$ & $\begin{array}{l}206 \\
254\end{array}$ & KNT1_RAT ${ }^{*}$ & 326 & KNT1_RAT ${ }^{*}$ & 123 & KNT1_RAT ${ }^{*}$ & 38 \\
\hline 7 & FIBG_RAT & 134 & FIBG_RAT & 98 & FIBG_RAT & 169 & - & - \\
\hline 8 & ARC1A_RAT* ${ }^{*}$ & 27 & SCO2_RAT $\Delta$ & 32 & FIBG_RAT & 237 & - & - \\
\hline 9 & ALBU_RAT & 239 & VIME_RAT & 35 & ALBU_RAT & 462 & BABA2_RAT* $\Delta$ & 33 \\
\hline 10 & FIBA_RAT $\Delta$ & 181 & BRMS1_RAT $^{*} \Delta$ & 34 & ALBU_RAT & 278 & - & - \\
\hline 11 & ALBU_RAT & 426 & NSF1_RAT $\Delta$ & 27 & ALBU_RAT & 357 & - & - \\
\hline 12 & FIBA_RAT $\Delta$ & 220 & HEMO_RAT & 241 & HEMO_RAT & 331 & BABA2_RAT $^{*} \Delta$ & 27 \\
\hline 13 & FIBA_RAT $\Delta$ & 336 & HEMO_RAT & 117 & HEMO_RAT & 375 & AMZ2_RAT $^{*}$ & 35 \\
\hline 14 & $\begin{array}{l}\text { Mixture } \\
\text { FIBB_RAT } \\
\text { FIBA_RAT } \Delta\end{array}$ & $\begin{array}{l}353 \\
190\end{array}$ & FIBB_RAT & 200 & FIBB_RAT & 249 & - & - \\
\hline 15 & FIBA_RAT $\Delta$ & 246 & FIBA_RAT $\Delta$ & 322 & FIBA_RAT $\Delta$ & 132 & - & - \\
\hline
\end{tabular}

Spot numbers correspond to those on Fig. $2 .{ }^{\star} \mathrm{MW}$ of identified protein does not correspond with its MW in gel map; $\Delta$, pI of identified protein does not correspond with its $\mathrm{pI}$ in gel map; X, spot was excised but protein was not identified with MS; - spot was not found on the gel. 


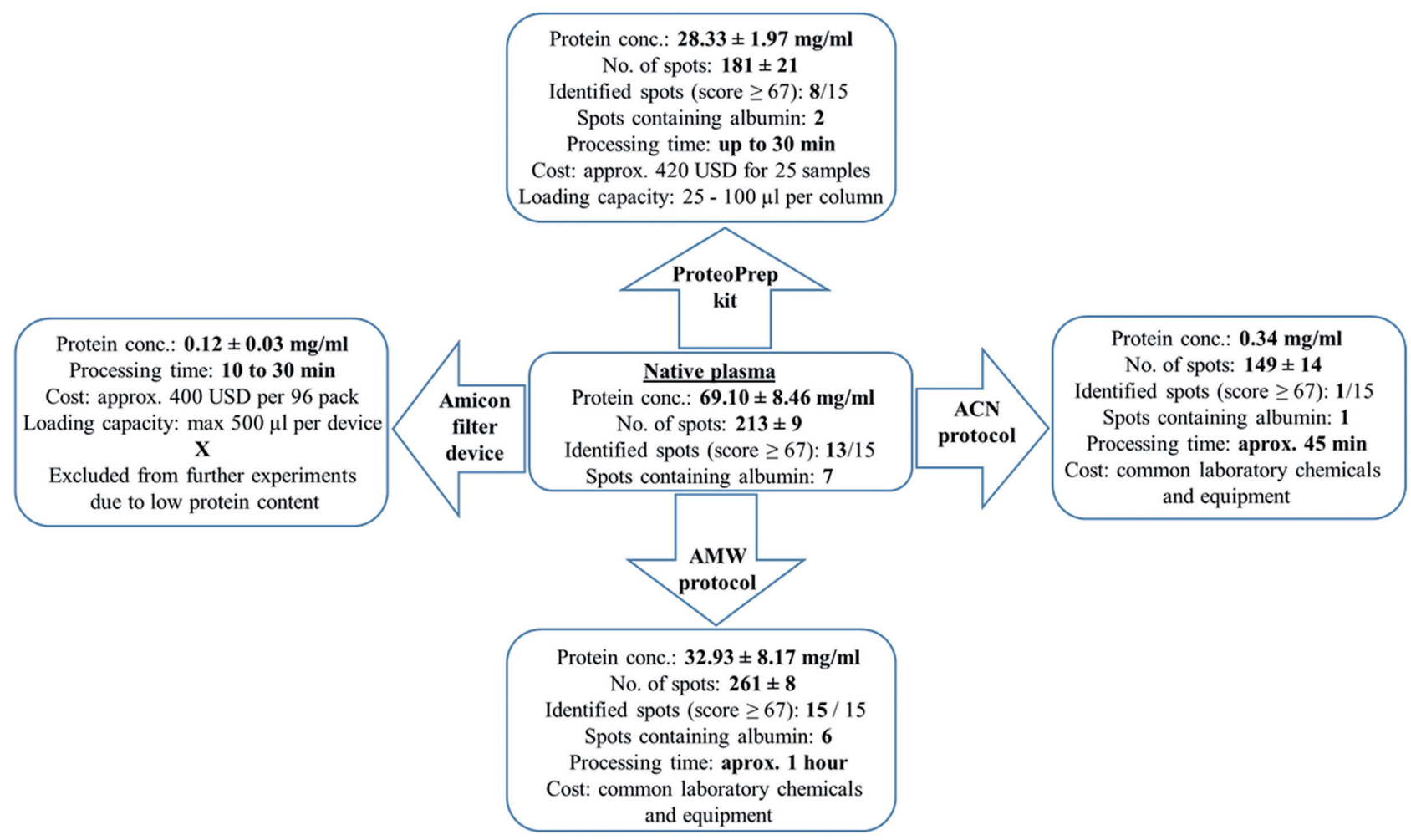

Figure 5. Scheme representing effectivity of different albumin removal methods. Highlighted by bold are important outcomes for evaluation of effectivity of the dealbumination method. ACN, acetonitrile; AMW, acetonitrile-methanol-water; conc, concentration.

AMW albumin-enriched fraction shows that high number of proteins was removed from the crude sample together with albumin.

\section{Discussion}

Using crude plasma for 2-DE leads to overloading of abundant proteins and poor spot resolution. Thus, albumin removal is a crucial preparation step for plasma proteome investigation with in-gel methods (Olver et al. 2010). In present work we tested four different albumin removal strategies for in-gel proteomic approaches. These methods were selected due to their applicability for 2-DE, high sample capacity, minimal preparation steps with short preparation time and convenient price. The above points are illustrated in Fig. 5.

The Amicon filter device was ruled out after initial protein concentration measurements. To achieve sufficient protein load for a single 2-DE nearly whole rat plasma sample would be needed, disabling further investigation of the sample.

Out of the remaining strategies the most sufficient one proved to be albumin removal with AMW protocol (incubation with acetonitrile and methanol) (Fig. 5). This depletion strategy significantly increased the number of spots and highlighted spots with molecular mass under $50 \mathrm{kDa}$. The spots on protein map were well focused and distinctively separated. Furthermore, all selected spots for mass spectrometry were identified with high Mascot score, thus improving the protein identification compared to crude plasma. On the other hand, albumin was still present in the depleted plasma sample but its density decreased (Fig. 2). Also, albumin was identified in several protein spots and 2-DE gel map of albumin-enriched fraction suggests that together with albumin part of protein content gets washed away (Fig. 4B). However, the 2-DE gel map from albuminenriched fraction overlaps with the one of depleted plasma and we assume that there is decrease in concentration of individual proteins and not in total number of proteins. Adding ACN to a sample weakens the hydrophobic interactions leading to protein denaturation and subsequent precipitation (Tucholska et al. 2010; Fernandez et al. 2011). The addition of ACN in a volume of at least $20 \%$ disrupts association of proteins with albumin, decreasing the chance of possible biomarker loss (Tirumalai et al. 2003; Kay et al. 2008). It was also shown that methanol precipitation leaves large amount of albumin in solution. Moreover, organic solvent precipitation removes organic-soluble contaminants such as salts and lipids which could interfere 
with IEF (Seong et al. 2017). Tucholska et al. (2010) previously reported successful implementation of organic solvent precipitation with ACN and methanol for low abundance blood proteins detection with liquid chromatography (LC) MS. Furthermore, also a usage of 70\% and 50\% cold acetone shows similar removal efficiency of albumin/IgG to that of two commercial kits, ProteoExtract and ProteoPrep (Seong et al. 2017). Albumin removal using organic solvents as acetonitrile and methanol removes albumin to some extent and can be used for biomarker discovery using proteomic in-gel methods.

Another tested organic precipitation strategy, ACN protocol, resulted in significant decrease in number of spots and the overall protein profile did not correspond to that of crude plasma. Out of all 15 proteins selected for identification, only one spot identified as albumin possessed significant Mascot score. This method selectively enriches proteins of hydrophobic nature and was developed mainly for LC-MS and multiple reaction monitoring (Kay et al. 2008; Fernandez et al. 2011) and seems unfit for 2-DE followed by MALDI-TOF MS.

The tested commercial ProteoPrep Blue Albumin and IgG Depletion Kit is based on Cibacron Blue stationary phase. Cibacron blue is a polycyclic anionic ligand that acts as a mimic of $\mathrm{NAD}^{+}$and $\mathrm{NADP}^{+}$but also through electrostatic, hydrophobic and other forces and it has been long used for protein purification (Riske et al. 2007; Fang and Zhang 2008; Pisanu et al. 2018). Successful use of Cibacron blue for biomarker discovery was already published (Ahmed et al. 2004). Its disadvantage is that this method also depletes albumin associated proteins and peptides. In present study we observed a slight decrease in number of spots in protein map of plasma depleted with PreoteoPrep Blue kit even though the spots were well separated with good resolution. The removal of albumin was sufficient with visible decrease of density on 1-DE gel (Fig. 2B) despite albumin still being in 2 spots. However, only about half of the proteins selected for identification reached significant Mascot score.

Furthermore, Pisanu et al. (2018), who compared Cibacron Blue based kit and six other commercial depletion kits (four based on immunoaffinity with antibody directed against specific proteins, one based on $\mathrm{G}$ protein with human serum albumin antibodies and last one based on the affinity for combinatorial peptide ligand library) on human serum found, that out of the tested depletion methods, the Cibacron Blue kit showed lowest increase in number of proteins and worst outcome in removal of albumin content. Highest increase in number of proteins was reached using peptide library approach, ProteoMiner and albumin was in human serum most completely removed after immunoaffinity SpinTrap kit.

It was shown that even removal of one major protein, like albumin, clearly allows the detection of new proteins. Also, there is limited beneficial impact increased drawbacks in removing associated proteins when depleting more than 12 HAPs (Roche et al. 2009). Interestingly enough, Grubbs et al. (2015), who tested albumin depletion methods on porcine serum reported that it is preferable for 2-DE to use crude plasma or serum with narrow $\mathrm{pH}$ range that isolate the albumin toward the edges of the gel.

It is important to note that studies focused on characterizing the albuminome, a subproteome consisting of the proteins and peptides associated with albumin were published and albuminome could also contain some potential disease biomarkers (Camaggi et al. 2010; Holewinski et al. 2013).

\section{Conclusion}

Removing albumin and other HAPs from blood plasma/ serum remains challenging task not only in our laboratory but for many research groups worldwide in different areas from medical, through veterinary to basic animal research.

Out of the four tested albumin depletion methods, precipitation with AMW protocol showed the best results. The protein spots were distinctively separated and the protein spot count after application of this method significantly increased. Also, AMW protocol improved protein identification with MALDI-TOF/TOF MS. However, the protein profile of albumin-enriched fraction shows that the method depletes also fraction of proteins with lower molecular mass.

Albumin depletion using organic solvents as acetonitrile and methanol removes albumin to some extent and can be used for biomarker discovery using proteomic in-gel methods. Simultaneously, it is advisable to pay attention to the albumin-enriched fraction and look for possible improvements to decrease the removal of proteins with lower molecular mass.

Acknowledgement. This work was supported by The Slovak Research and Development Agency under Grant APVV-15-0107, Scientific Grant Agency of the Ministry of Education of the Slovak Republic under Grant VEGA 1/0128/16 and the project "Competence Centre for Research and Development in the field of Diagnostics and Therapy of Oncological diseases", ITMS: 26220220153, co-financed from EU sources.

Conflict of interest. The authors report no conflict of interest.

\section{References}

Ahmed N, Barker G, Oliva KT, Hoffmann P, Riley C, Reeve S, Smith AI, Kemp BE, Quinn MA, Rice GE (2004): Proteomic-based identification of haptoglobin-1 precursor as a novel circulating biomarker of ovarian cancer. Br. J. Cancer. 91, 129-140 https://doi.org/10.1038/sj.bjc.6601882 
Anderson NL, Anderson NG (2002): The human plasma proteome. Mol. Cell. 1, 845-867 https://doi.org/10.1074/mcp.R200007-MCP200

Camaggi CM, Zavatto E, Gramantieri L, Camaggi V, Strocchi E, Righini R, Merina L, Chieco P, Bolondi L (2010): Serum albumin-bound proteomic signature for early detection and staging of hepatocarcinoma: sample variability and data classification. Clin. Chem. Lab. Med. 48, 1319-1326 https://doi.org/10.1515/cclm.2010.248

Fang X, Zhang WW (2008): Affinity separation and enrichment methods in proteomic analysis. J. Proteomics 71, 284-303 https://doi.org/10.1016/j.jprot.2008.06.011

Fernandez C, Santos HM, Ruíz-Romero C, Blanco FJ, CapeloMartínez JL (2011): A comparison of depletion versus equalization for reducing high-abundance proteins in human serum. Electrophoresis 32, 2966-2974 https://doi.org/10.1002/elps.201100183

Grubbs JK, Tuggle CK, Dekkers JCM, Boddicker NJ (2015): Investigation of the efficacy of albumin removal procedures on porcine serum proteome profile. J. Anim. Sci. 93, 1592-1598 https://doi.org/10.2527/jas.2014-8559

Guo X, Hao Y, Kamilijiang M, Hasimu A, Yuan J, Wu G, Reyimu H, Kadeer N, Abudula A (2015): Potential predictive plasma biomarkers for cervical cancer by 2D-DIGE proteomics and Ingenuity Pathway Analysis. Tumor Biol. 36, 1711-1720 https://doi.org/10.1007/s13277-014-2772-5

Haudenschild DR, Eldridge A, Lein PJ, Chromy BA (2014): High abundant protein removal from rodent blood for biomarker discovery. Biochem. Biophys. Res. Commun. 445, 84-89 https://doi.org/10.1016/j.bbrc.2014.09.137

Henkel AW, Muller K, Lewczuk P, Muller T, Marcus K, Kornhuber J, Wiltfang J (2012): Multidimensional plasma protein separation technique for identification of potential Alzheimer's disease plasma biomarkers: a pilot study. Biomarkers: a pilot study. J. Neural. Transm. 119, 779-788 https://doi.org/10.1007/s00702-012-0781-3

Holewinski RJ, Jin Z, Powell MJ, Maust MD, Van Eyk JE (2013): A fast and reproducible method for albumin isolation and depletion from serum and cerebrospinal fluid. Proteomics 13, 743-750 https://doi.org/10.1002/pmic.201200192

Hood BL, Zhou M, Chan KC, Lucas DA, Kim GJ, Issaq HJ, Veenstra TD, Conrads TP (2005): Investigation of the mouse serum proteome. J. Proteome Res. 4, 1561-1568 https://doi.org/10.1021/pr050107r

Kay R, Barton C, Matharoo-Ball L, Ratcliffe B, Brown P, Roberts J, Teale P, Creaser C (2008): Enrichment of low molecular weight serum proteins using acetonitrile precipitation for mass spectrometry based proteomic analysis. Rapid Commun. Mass Spectrom. 22, 3255-3260 https://doi.org/10.1002/rcm.3729

Lim LC, Looi ML, Zakaria SZ, Sagap I, Rose IM, Chin SF, Jamal $\mathrm{R}$ (2016): Identification of differentially expressed proteins in serum of colorectal cancer patients using 2D-DIGE Proteomics Analysis. Pathol. Oncol. Res. 22, 169-177 https://doi.org/10.1007/s12253-015-9991-y

Linke T, Doraiswamya S, Harrison EH (2007): Rat plasma proteomics: Effects of abundant protein depletion on proteomic analysis. J. Chromatogr. B. 849, 273-281 https://doi.org/10.1016/j.jchromb.2006.11.051

Olver CS, Webb TL, Long JL, Scherman H, Prenni JE (2010): Comparison of methods for depletion of albumin and IgG from equine serum. Vet. Clin. Pathol. 39, 337-345 https://doi.org/10.1111/j.1939-165X.2010.00241.x

Pisanu S, Biosa G, Carcangiu L, Uzzau, S, Pagnozzi, D (2018): Comparative evaluation of seven commercial products for human serum enrichment/depletion by shotgun proteomics. Talanta 185, 213-220 https://doi.org/10.1016/j.talanta.2018.03.086

Qui F, Hou T, Huang D, Xue Z, Lian D, Li Q, Lin W (2015): Evaluation of two high-abundance protein depletion kits and optimization of downstream isoelectric focusing. Mol. Med. Rep. 12, 7749-7755 https://doi.org/10.3892/mmr.2015.4417

Riske F, Smith M, Menon M, Goetschalck S, Goidsenhoven IV, Krul A, Pimpaneau V, Renaers I, Van Tichelt N, Van Houdt $\mathrm{K}$, et al. (2007): A potential generic downstream process using Cibacron Blue resin at very high loading capacity produces a highly purified monoclonal antibody preparation from cell culture harvest. J. Chromatogr. B. 848, 108-115 https://doi.org/10.1016/j.jchromb.2006.06.034

Roche S, Tiersb L, Provansal M, Sevenod M, Pivaa MT, Jouind P, Lehmanna S (2009): Depletion of one, six, twelve or twenty major blood proteins before proteomic analysis: The more the better? J. Proteomics 78, 945-951 https://doi.org/10.1016/j.jprot.2009.03.008

Seong Y, Yoo YS, Akter H, Kang MJ (2017): Sample preparation for detection of low abundance proteins in human plasma using ultra-high performance liquid chromatography coupled with highly accurate mass spectrometry. J. Chromatogr. B. 160, 272-280 https://doi.org/10.1016/j.jchromb.2017.06.023

Sharp PE, LaRegina MC (1998): The Laboratory Rat. CRC Press LLC, Boca Raton, FL https://doi.org/10.1201/9780849377198

Tirumalai RS, Chan KC, Prieto DA, Issaq H, Conrads TP (2003): Characterization of the low molecular weight human serum proteome. Mol. Cell. Proteomics 2, 1096-1103 https://doi.org/10.1074/mcp.M300031-MCP200

Tucholska M, Florentinus A, Williams D, Marshall JG (2010): The endogenous peptides of normal human serum extracted from the acetonitrile-insoluble precipitate using modified aqueous buffer with analysis by LC-ESI-Paul ion trap and Qq-TOF. J. Proteomics 73, 1254-1269 https://doi.org/10.1016/j.jprot.2010.02.022

Tucholska M, Scozzaro S, Williams D, Ackloo S, Lock C, Siu KWM, Evans KR, Marshall JG (2007): Endogenous peptides from biophysical and biochemical fractionation of serum analyzed by matrix-assisted laser desorption/ionization and electrospray ionization hybrid quadrupole time-of-flight. Anal. Biochem. 370, 228-245

https://doi.org/10.1016/j.ab.2007.07.029

Received: January 9, 2019

Final version accepted: March 12, 2019

First published online: June 20, 2019 
Supplementary Material

\title{
A comparison of albumin removal procedures for proteomic analysis of blood plasma
}

\author{
Anna Tomascova ${ }^{1}$, Jan Lehotsky ${ }^{1,2}$, Dagmar Kalenska ${ }^{1}$, Eva Baranovicova ${ }^{2}$, Peter Kaplan ${ }^{1,2}$ \\ and Zuzana Tatarkova ${ }^{1}$ \\ ${ }^{1}$ Department of Medical Biochemistry, Jessenius Faculty of Medicine in Martin, Comenius University in Bratislava, Martin, Slovakia \\ ${ }^{2}$ Department of Neuroscience, Biomedical Centre Martin, Jessenius Faculty of Medicine in Martin, Comenius University in \\ Bratislava, Martin, Slovakia
}

\section{Supplementary Tables}

Table S1. Mass spectrometry identification details for identified proteins from 1-DE

\begin{tabular}{lcccccc}
\hline Protein & UniProt ID & $\begin{array}{c}\text { MW } \\
\mathbf{( k D a )}\end{array}$ & pI & $\begin{array}{c}\text { Protein sequence } \\
\text { coverage (\%) }\end{array}$ & $\begin{array}{c}\text { Total Mascot } \\
\text { score }\end{array}$ & Expected MS \\
\hline Albumin & ALBU_RAT & 70.68 & 6.09 & 20 & 233 & $4.00 \mathrm{E}-20$ \\
Apolipoprotein A-I & APOA1_RAT & 30.1 & 5.52 & 57 & 309 & $1.00 \mathrm{E}-27$ \\
Apolipoprotein A-IV & APOA4_RAT & 44.43 & 5.15 & 16 & 211 & $6.40 \mathrm{E}-18$ \\
C-typelectine domain family 11 member A & CLC11_RAT & 36.71 & 5.28 & 1 & 21 & 6.4 \\
Gastrin-releasing peptide & GRP_RAT & 15.75 & 6.28 & 20 & 26 & 2.3 \\
Hemoglobin subunit beta-1 & HBB1_RAT & 16.08 & 7.88 & 32 & 132 & $5.10 \mathrm{E}-10$ \\
Hemopexin & HEMO_RAT & 52.06 & 7.58 & 19 & 102 & $5.10 \mathrm{E}-07$ \\
Serotransferrin & TRFE_RAT & 78.51 & 7.14 & 16 & 164 & $3.20 \mathrm{E}-13$ \\
Transthyretin & TTHY_RAT & 15.82 & 5.77 & 39 & 92 & $4.60 \mathrm{E}-06$ \\
Vitamin D-binding protein & VTDB_RAT & 55.11 & 5.65 & 20 & 169 & $1.00 \mathrm{E}-13$ \\
\hline
\end{tabular}

Correspondence to: Zuzana Tatarkova, Department of Medical Biochemistry, Jessenius Faculty of Medicine, Mala Hora 4, 03601 Martin, Slovakia

E-mail: Zuzana.Tatarkova@jfmed.uniba.sk 
Table S2. Mass spectrometry identification details for crude plasma protein map

\begin{tabular}{|c|c|c|c|c|c|c|}
\hline Spot no. & UniProt ID & MW (kDa) & pI & Protein sequence coverage (\%) & Total Mascot score & Expected MS \\
\hline 1 & ALBU_RAT & 70.68 & 6.09 & 21 & 358 & $1.30 \mathrm{E}-32$ \\
\hline 2 & ALBU_RAT & 70.68 & 6.09 & 26 & 185 & $2.50 \mathrm{E}-15$ \\
\hline 3 & ALBU_RAT & 70.68 & 6.09 & 11 & 231 & $6.40 \mathrm{E}-20$ \\
\hline 4 & ALBU_RAT & 70.68 & 6.09 & 11 & 196 & $2.00 \mathrm{E}-16$ \\
\hline 5 & $\begin{array}{c}\text { SPRYZ_RAT } \\
\text { mix. }\end{array}$ & 22.12 & 6.22 & 15 & 24 & 33 \\
\hline \multirow[t]{2}{*}{6} & KNT1_RAT & 48.83 & 6.08 & 28 & 206 & $2 \mathrm{E}-17$ \\
\hline & ALBU_RAT & 70.68 & 6.09 & 23 & 254 & $3.2 \mathrm{E}-22$ \\
\hline 7 & FIBG_RAT & 51.23 & 5.62 & 31 & 134 & $3.20 \mathrm{E}-10$ \\
\hline 8 & ARC1A_RAT & 42.14 & 8.46 & 18 & - & 18 \\
\hline 9 & ALBU_RAT & 70.68 & 6.09 & 15 & 239 & $1.00 \mathrm{E}-20$ \\
\hline 10 & FIBA_RAT & 87.37 & 5.51 & 15 & 181 & $6.40 \mathrm{E}-15$ \\
\hline 11 & ALBU_RAT & 70.68 & 6.09 & 27 & 426 & $2.00 \mathrm{E}-39$ \\
\hline 12 & FIBA_RAT & 87.37 & 5.51 & 17 & 220 & $8.00 \mathrm{E}-19$ \\
\hline 13 & $\begin{array}{l}\text { FIBA_RAT } \\
\text { mix. }\end{array}$ & 87.37 & 5.51 & 27 & 336 & $2.00 \mathrm{E}-30$ \\
\hline \multirow[t]{2}{*}{14} & FIBB_RAT & 54.83 & 7.9 & 52 & 353 & $4 e-32$ \\
\hline & FIBA_RAT & 87.37 & 5.51 & 23 & 190 & $8 e-16$ \\
\hline 15 & FIBA_RAT & 87.37 & 5.51 & 26 & 246 & $2.00 \mathrm{E}-21$ \\
\hline
\end{tabular}

Spot numbers correspond to those on Fig. 2A.

Table S3. Mass spectrometry identification details for ProteoPrep kit plasma protein map

\begin{tabular}{lcccccc}
\hline Spot no. & UniProt ID & MW $(\mathbf{k D a})$ & pI & Protein sequence coverage (\%) & $\begin{array}{c}\text { Total Mascot } \\
\text { score }\end{array}$ & Expected MS \\
\hline 1 & RPN1_RAT & 68.376 & 6.05 & 9 & 20 & 20 \\
2 & ALBU_RAT & 70.682 & 6.09 & 28 & 277 & $1.60 \mathrm{E}-24$ \\
3 & ALBU_RAT & 70.682 & 6.09 & 25 & 357 & $1.60 \mathrm{E}-32$ \\
4 & - & - & - & - & - & - \\
5 & TBB3_RAT & 50.842 & 9.4 & 12 & 329 & $2.00 \mathrm{E}-29$ \\
6 & KNT1_RAT & 48.828 & 6.08 & 40 & 98 & $1.30 \mathrm{E}-06$ \\
7 & FIBG_RAT & 51.228 & 5.62 & 10 & 32 & 4.8 \\
8 & SCO2_RAT & 57.491 & 9.35 & 10 & 35 & 2.7 \\
9 & VIME_RAT & 53.757 & 5.06 & 13 & 34 & 3.1 \\
10 & BRMS1_RAT & 28.459 & 4.67 & 24 & 241 & 1.7 \\
11 & NSF1_RAT & 50.38 & 8.92 & 25 & 117 & $6.40 \mathrm{E}-21$ \\
12 & HEMO_RAT & 52.06 & 7.58 & 40 & 200 & $1.60 \mathrm{E}-08$ \\
13 & HEMO_RAT & 52.06 & 7.58 & 25 & 322 & $8.00 \mathrm{E}-17$ \\
14 & FIBB_RAT & 54.828 & 7.9 & 5.51 & $5.10 \mathrm{E}-29$ \\
15 & FIBA_RAT & 87.373 & 5.51 & 32 \\
\hline
\end{tabular}

Spot numbers correspond to those on Fig. 2B. 
Table S4. Mass spectrometry identification details for AMW plasma protein map

\begin{tabular}{lcccccc}
\hline Spot no. & UniProt ID & MW $(\mathbf{k D a})$ & pI & Protein sequence coverage (\%) & Total Mascot score & Expected MS \\
\hline 1 & ALBU_RAT & 70.682 & 6.09 & 31 & 419 & $1.00 \mathrm{E}-38$ \\
2 & ALBU_RAT & 70.682 & 6.09 & 16 & 337 & $1.60 \mathrm{E}-30$ \\
3 & ALBU_RAT & 70.682 & 6.09 & 22 & 288 & $1.30 \mathrm{E}-25$ \\
4 & TRFE_RAT & 78.512 & 7.14 & 21 & 113 & $4.00 \mathrm{E}-34$ \\
5 & KNT1_RAT & 48.826 & 6.08 & 22 & 123 & $6.40 \mathrm{E}-08$ \\
6 & KNT1_RAT & 48.826 & 6.08 & 21 & 169 & $4.00 \mathrm{E}-09$ \\
7 & FIBG_RAT & 51.228 & 5.62 & 35 & 237 & $1.00 \mathrm{E}-13$ \\
8 & FIBG_RAT & 51.228 & 5.62 & 46 & 462 & $1.60 \mathrm{E}-20$ \\
9 & ALBU_RAT & 70.682 & 6.09 & 31 & 278 & $5.10 \mathrm{E}-43$ \\
10 & ALBU_RAT & 70.682 & 6.09 & 40 & 357 & $1.30 \mathrm{E}-24$ \\
11 & ALBU_RAT & 70.682 & 6.09 & 30 & 331 & $1.60 \mathrm{E}-32$ \\
12 & HEMO_RAT & 52.06 & 7.58 & 33 & 375 & $6.40 \mathrm{E}-30$ \\
13 & HEMO_RAT & 52.06 & 7.58 & 41 & 249 & $2.50 \mathrm{E}-34$ \\
14 & FIBB_RAT & 54.828 & 7.9 & & & $1.00 \mathrm{E}-21$ \\
\hline
\end{tabular}

Spot numbers correspond to those on Fig. 2C. 